\title{
ASC in Renal Collecting Duct Epithelial Cells Contributes to Inflammation and Injury after Unilateral Ureteral Obstruction
}

\author{
Takanori Komada, ${ }^{* \dagger}$ Fumitake Usui, ${ }^{*}$ Koumei Shirasuna, ${ }^{*}$ Akira Kawashima, ${ }^{*}$ Hiroaki Kimura, ${ }^{*}$ Tadayoshi Karasawa, ${ }^{*}$ \\ Satoshi Nishimura, ${ }^{\ddagger}$ Junji Sagara, ${ }^{\S}$ Tetsuo Noda, ${ }^{\top}$ Shun'ichiro Taniguchi, ${ }^{\S}$ Shigeaki Muto, ${ }^{\dagger}$ Daisuke Nagata, ${ }^{\dagger}$
} Eiji Kusano, ${ }^{\dagger}$ and Masafumi Takahashi*

\begin{abstract}
From the Division of Inflammation Research, ${ }^{*}$ Center for Molecular Medicine, and the Department of Nephrology, ${ }^{\dagger}$ Jichi Medical University, Tochigi; the Department of Cardiovascular Medicine and Translational Systems Biology and Medicine Initiative, ${ }^{\ddagger}$ the University of Tokyo, Tokyo; the Department of Molecular Oncology, ${ }^{\S}$ Shinshu University Graduate School of Medicine, Nagano; and the Department of Cell Biology, "Japanese Foundation for Cancer Research, Cancer Institute, Tokyo, Japan
\end{abstract}

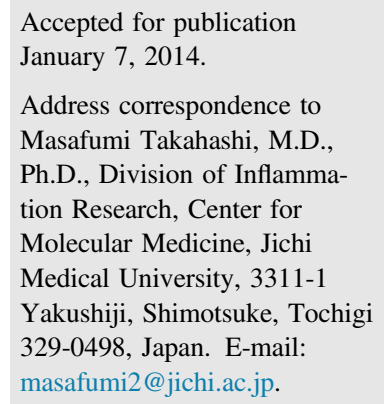

\begin{abstract}
Inflammation plays a crucial role in the pathophysiological characteristics of chronic kidney disease; however, the inflammatory mechanisms underlying the chronic kidney disease process remain unclear. Recent evidence indicates that sterile inflammation triggered by tissue injury is mediated through a multiprotein complex called the inflammasome. Therefore, we investigated the role of the inflammasome in the development of chronic kidney disease using a murine unilateral ureteral obstruction (UU0) model. Inflammasome-related molecules were up-regulated in the kidney after UU0. Apoptosisassociated speck-like protein containing a caspase recruitment domain deficiency significantly reduced inflammatory responses, such as inflammatory cell infiltration and cytokine expression, and improved subsequent renal injury and fibrosis. Furthermore, apoptosis-associated speck-like protein containing a caspase recruitment domain was specifically up-regulated in collecting duct (CD) epithelial cells of the UU0-treated kidney. In vitro experiments showed that extracellular adenosine triphosphate (ATP) induced inflammasome activation in $C D$ epithelial cells through $P 2 X_{7}$-potassium efflux and reactive oxygen species-dependent pathways. These results demonstrate the molecular basis for the inflammatory response in the process of chronic kidney disease and suggest the CD inflammasome as a potential therapeutic target for preventing chronic kidney disease progression. (Am J Pathol 2014, 184: 1287-1298; http://dx.doi.org/10.1016/j.ajpath.2014.01.014)
\end{abstract}

Chronic kidney disease (CKD) is a major public health problem worldwide. More than 20 million adults in the United States are estimated to have some level of CKD, and 0.5 million patients reach end-stage renal disease. ${ }^{1}$ Recent evidence suggests that CKD is accompanied by inflammatory responses in the kidney, characterized by up-regulation of inflammatory cytokines, infiltration of inflammatory cells, and accumulation of myofibroblasts, which can lead to tubulointerstitial injury and kidney fibrosis. However, the molecular mechanisms underlying inflammatory responses in the development of CKD remain to be examined.

Accumulating evidence indicates that inflammation in the absence of pathogens, referred to as sterile inflammation, is mediated through the inflammasome, a large cytosolic multiple protein complex, and regulates proinflammatory cytokine IL-1 $\beta$ production. ${ }^{2,3}$ The inflammasome contains Nod-like receptors (NLRs) associated with apoptosis-associated speck-like protein containing a caspase recruitment domain (ASC), which recruits caspase- 1 and induces its activation. Because caspase- 1 is known as an IL- $1 \beta$-converting enzyme,

\footnotetext{
Supported by the Japan Society for the Promotion of Science Funding Program for Next Generation World-Leading Researchers (NEXT Program), initiated by the Council for Science and Technology Policy (M.T.), NEXTsupported program for the Strategic Foundation at Private Universities (M.T.), and Jichi Medical University grant-in-aid for research activity start-up (T.K.).

Disclosures: None declared.
} 
it processes pro- - IL- $1 \beta$ into its mature form and induces IL- $1 \beta$ release, causing inflammation and tissue damage. We recently showed the importance of the inflammasome in the pathogenesis of several disease conditions. ${ }^{4-7}$ By using mice deficient in ASC and caspase-1, we showed that inflammasome activation in cardiac fibroblasts, but not in cardiomyocytes, is crucially involved in the initial inflammatory response after myocardial ischemia-reperfusion (I/R) injury. ${ }^{6}$ The inflammasome is also involved in the pathophysiological characteristics of vascular injury, and ASC deficiency reduced the infiltration of inflammatory cells and the expression of inflammatory cytokines, thereby attenuating neointimal formation after vascular injury. ${ }^{5}$ Furthermore, the inflammasome is implicated in vascular inflammation and atherosclerosis development induced by hypercholesterolemia. ${ }^{7,8}$ These findings indicate that the inflammasome can initiate sterile inflammatory responses in disease. Our findings are further supported by reports describing that the inflammasome is a critical mediator of other sterile inflammatory diseases, including gout, pseudogout, asbestosis, silicosis, Alzheimer disease, metabolic syndrome, and type 2 diabetes. ${ }^{2,3}$ Therefore, we hypothesized that the inflammasome can mediate inflammatory responses in the process of CKD. Indeed, Vilaysane et $\mathrm{al}^{9}$ recently showed that NLR family pyrin domaincontaining 3 (NLRP3) deficiency improved renal injury and fibrosis in a murine model of unilateral ureteral obstruction (UUO), which is frequently used as a model of obstructive nephropathy and CKD. However, Shigeoka et $\mathrm{al}^{10}$ reported that reduction of renal $\mathrm{I} / \mathrm{R}$ injury was observed in mice deficient in NLRP3, but not in other inflammasome components, and concluded that NLRP3 contributes to the development of I/R injury through an inflammasome-independent pathway in the kidney. Thus, the contribution of the inflammasome to the development of CKD remains to be investigated in mice deficient in other inflammasome components.

Herein, we used mice deficient in ASC, a central component of the inflammasome assembly, ${ }^{2,4}$ and examined whether the inflammasome plays a substantial role in renal injury and fibrosis after ureteral obstruction. We demonstrated that ASC deficiency attenuates renal inflammatory and fibrotic responses after UUO. Furthermore, we identified that collecting duct (CD) epithelial cells are responsible for ASC upregulation in the kidney. This study describes the role of the inflammasome in the pathophysiological characteristics of renal injury and fibrosis and suggests that the inflammasome is a therapeutic target for the treatment of kidney disease.

\section{Materials and Methods}

\section{Animal Models}

All experiments were performed in accordance with the Jichi Medical University Guide for Laboratory Animals. C57BL/6J [wild-type (WT)] mice were purchased from Japan SLC, Inc. (Tokyo). ASC ${ }^{-/-}$mice (C57BL/6J genetic background) were generated as described previously. ${ }^{5,6,11}$
Mice were fed, watered, and maintained on a 12-hour light and dark cycle. UUO models were produced in 8- to 10 -week-old male mice by left ureteral ligation, as described previously. ${ }^{12}$ Complete ureteral obstruction was made by double ligation with 4-0 silk sutures. Mice were sacrificed, and the kidneys were analyzed on specified days.

\section{Real-Time RT-PCR}

Total RNA was prepared from the kidneys using ISOGEN (Nippon Gene Co, Ltd, Toyama, Japan), according to the manufacturer's instructions. Real-time RT-PCR analysis was performed using the Takara TP960 PCR Thermal Cycler Dice Detection System (Takara Bio Inc., Shiga, Japan) to detect the mRNA expression. The following primers (oligonucleotide sequences are provided in parentheses in the order of antisense and sense primers) were used: Nlrp3 (5'-CGAGACCTCTGGGAAAAAGCT- $3^{\prime}$ and 5'-GCATACCATAGAGGAATGTGATGTACA- $\left.3^{\prime}\right)$, Asc (5'-GCTGAGCAGCTGCAAACGAC- $3^{\prime}$ and $5^{\prime}$-ACTTCTGTGACCCTGGCAATGAG- $3^{\prime}$ ), Casp1 (5'-GATGGCACATTTCCAGGACTGA- ${ }^{\prime}$ and $5^{\prime}$ TGTTGCAGATAATGAGGGCAAGAC-3'), Illb (5'-TGAAGTTGACGGACCCCAAA- $3^{\prime}$ and $5^{\prime}$-TGATGTGCTGCTGTGAGATT-3'), Nlrc4 (5'-ATGCTCATCACCGTGTGGAG-3' and $5^{\prime}$-GCCAGACTCGCCTTCAATCA-3'), Aim2 (5'-TTGTATCTAGGCTGATCCTGGGAC- $3^{\prime}$ and $5^{\prime}$-ACCTGCACTTTGAATCAGGTGGTC-3'), Ccl2 (5'-GGCTCAGCCAGATGCAGTTAAC- $3^{\prime}$ and 5'-GCCTACTCATTGGGATCATCTTG-3'), Il6 (5'-ACAACCACGGCCTTCCCTACTT- $3^{\prime}$ and $5^{\prime}$-CACGATTTCCCAGAGAACATGTG$\left.3^{\prime}\right)$, Tnfa $\left(5^{\prime}\right.$-CCCCAAAGGGATGAGAAGTTC- $3^{\prime}$ and $5^{\prime}$ GCTTGTCACTCGAATTTTGAGAA-3'), Col1a1 (5'-CGGAGAAGAAGGAAAACGAGGAG- $3^{\prime}$ and $5^{\prime}$-CACCATCAGCACCAGGGAAAC-3'), Col3a1 (5'-CCCAACCAGAGATCCCATT- $3^{\prime}$ and $5^{\prime}$-GAAGCACAGGAGCAGGTGTAGA-3'), Tgfb1 (5'-GCAACATGTGGAACTCTACCAGA$3^{\prime}$ and $5^{\prime}$-GACGTCAAAAGACAGCCACTCA-3'), Mmp2 (5'-GACATACATCTTTGCAGGAGACAAG- ${ }^{\prime}$ and $5^{\prime}$ TCTGCGATGAGCTTAGGGAAA-3'), Mmp9 (5'-CCTGGAACTCACACGACATCTTC- $3^{\prime}$ and 5'-TGGAAACTCACACGCCAGAA-3'), Timp1 (5'-GTAAGGCCTGTAGCTGTGCC- $3^{\prime}$ and $5^{\prime}$-AGGTGGTCTCGTTGATTTCT- ${ }^{\prime}$ ), and Gapdh (5'-TGTGTCCGTCGTGGATCTGA- $3^{\prime}$ and $5^{\prime}$-TTCGTGTTGAAGTCGCAGGAG-3').

The expression levels of each target gene were normalized by subtracting the corresponding glyceraldehyde-3phosphate dehydrogenase (GAPDH) cycle threshold $\left(\mathrm{C}_{\mathrm{T}}\right)$ values; this was done by using the $\Delta \Delta \mathrm{C}_{\mathrm{T}}$ comparative method.

\section{Histological and IHC Studies}

Kidneys were harvested, fixed in $10 \%$ formalin, and embedded in paraffin. The sections ( $2 \mu \mathrm{m}$ thick) were used for staining with $\mathrm{H} \& \mathrm{E}$, PAS, picrosirius red, or immunohistochemistry (IHC) using standard protocols. Tubulointerstitial injury was scored in at least five images randomly captured 
with $\times 200$ magnification. The scoring on PAS samples was performed, as described previously, ${ }^{9}$ according to the following semiquantitative grades: grade 0 , normal; grade 1 , $<20 \%$; grade $2,20 \%$ to $39 \%$; grade $3,40 \%$ to $59 \%$; grade $4,60 \%$ to $79 \%$; and grade $5, \geq 80 \%$. The area of fibrosis on picrosirius red sections was assessed in 10 random nonoverlapping fields $(\times 200$ magnification) using Leica Application Suite software version 3.4.1 (Leica Microsystems GmbH, Wetzlar, Germany) and Adobe Photoshop CS software version 8 (Adobe Systems Inc., San Jose, CA).

The IHC analyses of paraffin-embedded sections were performed to detect $\mathrm{F} 4 / 80$ for macrophage infiltration using a monoclonal rat anti-mouse F4/80 antibody (clone A3-1; AbD Serotec, Raleigh, NC). Briefly, deparaffinized kidney sections were boiled in Target Retrieval Solution (Dako, Carpinteria, CA), blocked with $2 \%$ casein, and incubated overnight in the primary antibodies. This was followed by incubation with biotin-conjugated secondary antibodies. The sections were washed and treated with avidin-peroxidase (avidin-biotin complex kit; Vector Laboratories, Burlingame, $\mathrm{CA})$. The reaction was developed using a diaminobenzidine substrate kit (Vector Laboratories), followed by hematoxylin counterstaining. No signals were detected when speciesmatched IgG (Vector Laboratories) was used instead of the primary antibody as a negative control. Expression of $\alpha$-smooth muscle actin (SMA) was assessed IHC using alkaline phosphatase-conjugated monoclonal anti- $\alpha$-SMA antibody (clone 1A4; Sigma, St. Lous, MO). Alkaline Phosphatase Substrate Kit I (Vector Laboratories) was used for colorimetric visualization. Other primary antibodies include the following: rabbit anti-mouse apoptosis-associated specklike protein containing CARD antibody (ASC; Enzo Life Sciences, Inc., Farmingdale, NY), polyclonal goat antiaquaporin-2 antibody [AQP2 (C-17); Santa Cruz Biotechnology, Inc., Dallas, TX], polyclonal goat anti-calbindin D28K antibody [CaBP (C-20); Santa Cruz Biotechnology, Inc.], and polyclonal rabbit anti-aquaporin-1 antibody [AQP1 (H-55); Santa Cruz Biotechnology, Inc.]. The polymeric method using Histofine Simple Stain MAX PO (Nichirei Bioscience, Tokyo, Japan) was indicated as an alternative to the avidin-biotin complex method, if appropriate. For immunofluorescence staining, Alexa 594- or fluorescein isothiocyanate (FITC)-conjugated secondary antibodies were used. At least 10 random fields of $\times 200$ magnification were analyzed for measurement in a similar manner. FITC-conjugated Dolichos biflorus agglutinin (DBA; Vector Laboratories) lectin was used to stain CD epithelial cells. The stained sections were digitalized and analyzed using a microscope (model FSX-100; Olympus, Tokyo) or a confocal laser-scanning microscope (model FV-10i; Olympus).

\section{Flow Cytometric Analysis}

Kidney cells were isolated and analyzed by flow cytometry, as described previously. ${ }^{13}$ In brief, the whole kidney was cut into small pieces in ice-cold PBS with $1 \%$ fetal calf serum, homogenized, filtered, and then centrifuged at $250 \times g$ for 10 minutes. Cells were washed, and centrifugation was repeated. After removing erythrocytes using BD PharmLyse buffer (BD Biosciences, San Jose, CA), samples were subjected to flow cytometry analysis using FACSCalibur (BD Biosciences). Anti-mouse allophycocyanin-conjugated CD45, phycoerythrin-conjugated CD11b, FITC-conjugated F4/80, FITC-conjugated CD45R (eBioscience, San Diego, CA), FITC-conjugated CD3, Alexa 488-conjugated CD19 (AbD Serotec), and phycoerythrin-conjugated Gr1 (Miltenyi Biotec Bergisch Gladbach, Nordrhein-Westfalen, Germany) antibodies were used to detect leukocytes, macrophages, $\mathrm{T}$ cells, B cells, and neutrophils. Isotype control antibodies were used to determine background staining.

\section{Detection of Apoptosis}

Apoptotic cells were identified using a TUNEL staining kit (Roche Diagnostics, Mannheim, Germany), according to the manufacturer's instructions.

\section{Cell Culture and in Vitro Experiments}

Primary CD cells were isolated from mouse kidneys and cultured according to the previously described methods. ${ }^{14,15}$ Briefly, kidneys were immediately removed after mice were sacrificed, washed with PBS, decapsulated, and bisected. The papillae were immediately placed in ice-cold PBS and minced with scissors, followed by immersion in Dulbecco's modified Eagle's/F-12 medium (Life Technologies, Carlsbad, CA) containing $15 \mathrm{mmol} / \mathrm{L}$ HEPES, $0.1 \%$ type I collagenase, and $0.1 \%$ bovine serum albumin. After 2 hours of incubation, the suspension was diluted in two volumes of distilled water to disrupt non-CD cells. The tube was centrifuged at $210 \times g$ for 5 minutes at $4{ }^{\circ} \mathrm{C}$, the pellet was resuspended, and the procedure was repeated twice. After filtration through a 70- $\mu \mathrm{m}$ cell strainer, the cells in the suspension were plated into dishes. The CD cells were grown in Dulbecco's modified Eagle's/F-12 medium supplemented with $15 \mathrm{mmol} / \mathrm{L}$ HEPES, $10 \%$ fetal calf serum, and 5\% antibiotic antimycotic solution (Sigma) at $37^{\circ} \mathrm{C}$ in a $5 \% \mathrm{CO}_{2}$ atmosphere for 6 days. The $\mathrm{CD}$ cells were clearly stained with the general CD marker, DBA lectin. This DBA staining was abolished by pretreatment with $N$-acetylgalactosamine. After serum starvation and 8 hours of priming with low-dose lipopolysaccharide (LPS; $10 \mathrm{ng} / \mathrm{mL}$ ), the confluent CD epithelial cells were treated with $5 \mathrm{mmol} / \mathrm{L}$ ATP in the presence or absence of glibenclamide (Sigma), $N$-acetyl cysteine (NAC; Wako Pure Chemical Industries, Ltd, Osaka, Japan), and YVAD-FMK (MBL, Nagoya, Japan) for 3 hours. The levels of IL-1 $\beta$ in the culture supernatant were assessed using a mouse enzyme-linked immunosorbent assay kit (Mouse IL-1ß/IL-1F2 DuoSet; R\&D Systems, Minneapolis, MN), according to the manufacturer's instructions. All other reagents were obtained from Sigma, unless otherwise specified. 


\section{Western Blot Analysis}

The expression levels of ASC, NLRP3, and IL-1 $\beta$ were analyzed using Western blot analysis. ${ }^{5,6}$ Primary CD cells and peritoneal macrophages (thioglycollate-elicited peritoneal exudate cells) were isolated from mice. Cell lysates were prepared and subjected to SDS-PAGE under reducing conditions, and the protein bands were transferred to a polyvinylidene difluoride membrane. The membrane was blocked overnight at $4{ }^{\circ} \mathrm{C}$ with $2 \%$ casein and then incubated for 1 hour at room temperature with the primary antibodies, followed by incubation for 1 hour with the secondary antibody, conjugated horseradish peroxidase (HRP). Primary antibodies against ASC (Enzo Life Sciences, Inc.), NLRP3 (R\&D Systems), IL-1 $\beta$ (R\&D Systems), and $\beta$-actin (Sigma) were used. The secondary antibody was HRP-conjugated anti-IgG (Jackson ImmunoResearch Laboratories, Inc., West Grove, PA). Immunoreactive bands were visualized by a Western BLoT HRP Chemiluminescent Substrate system (Takara Bio Inc.). The expression levels of $\beta$-actin served as an internal control for protein loading.

\section{Measurement for Caspase-1 Activity}

Caspase- 1 activity was analyzed using the carboxyfluorescein FLICA Caspase-1 assay kit (Immunochemistry Technologies, Bloomington, $\mathrm{MN}$ ), according to the manufacturer's instructions. Fluorescence was detected by using confocal laser-scanning microscopy (model FV-10i; Olympus).

\section{Statistical Analysis}

Data are expressed as means \pm SEM. An unpaired $t$-test was used to compare two groups. For comparisons between multiple groups, the significance of differences in between-group means was determined by one-way analysis of variance combined with the Tukey-Kramer test or Dunnett's post hoc test. Nonparametric data were analyzed using the Kruskal-Wallis test, as appropriate. All analyses were performed using the Statistical Package for the Social Sciences (SPSS) Software version 19 (IBM, New York, NY). $P<0.05$ was considered statistically significant.

\section{Results}

Expression of Inflammasome-Related Molecules after UU0

We first examined if inflammasome-related molecules are up-regulated in the kidney after UUO induction. Real-time RT-PCR analysis revealed that the mRNA expression of Nlrp3, Asc, Casp1, and Il1b was time dependently increased in the ligated kidney compared with expression in the contralateral kidney (Figure 1, A-D), whereas no dramatic changes were observed in the expression of other inflammasome-related genes, Nlrc4 and Aim2, between the ligated and contralateral kidneys (Figure 1, E and F). These
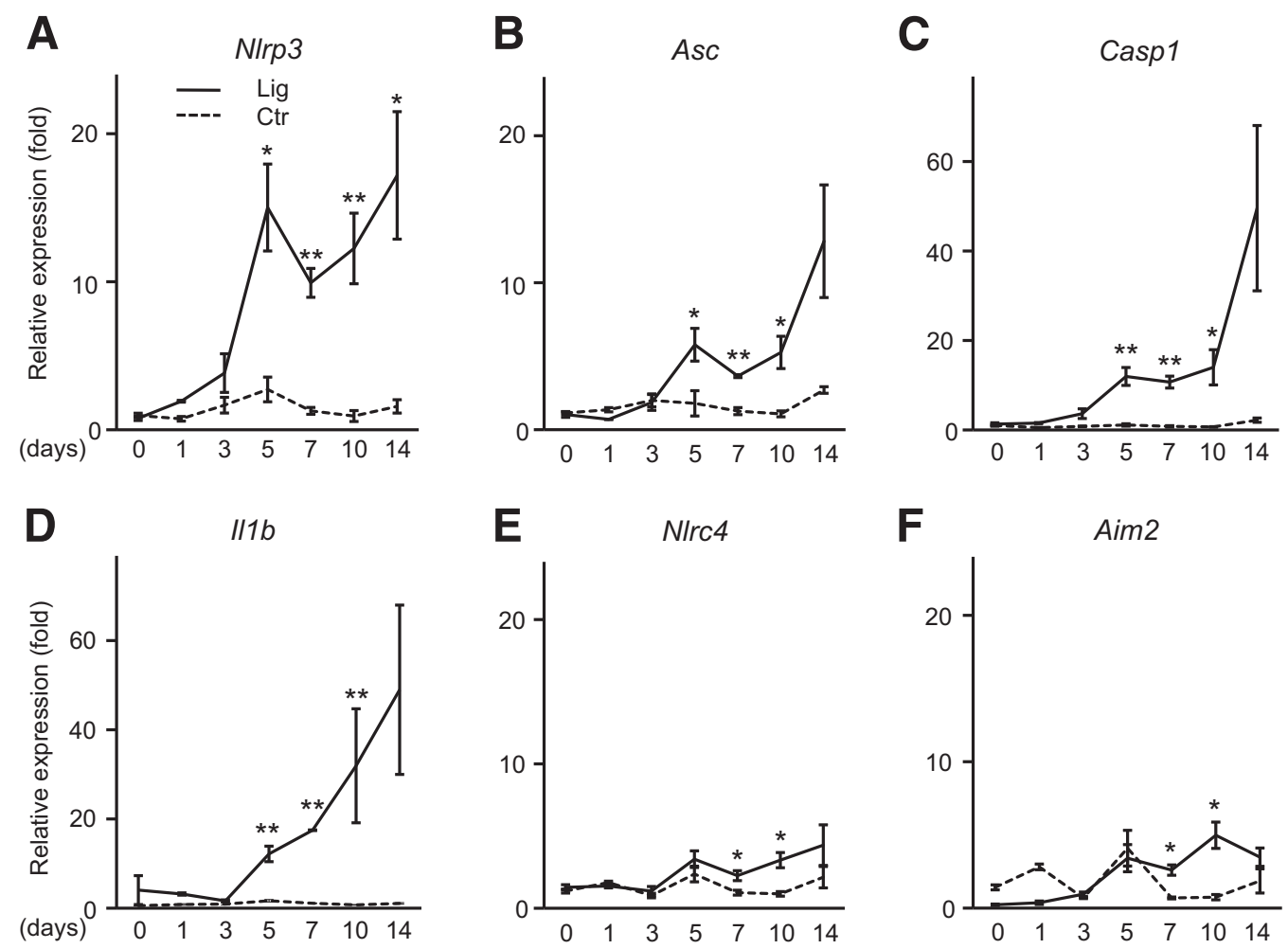

Figure 1 Role of the inflammasome in UUO. A-E: Mice were sacrificed at the indicated days after UUO induction. Total RNA was extracted from the contralateral (Ctr) and ligated (Lig) kidneys of WT mice on the indicated days after UUO. Renal mRNA levels of Nlrp3 (A), Asc (B), Casp1 (C), Il1b (D), Nlrc4 (E), and Aim2 (F) were assessed by using real-time RT-PCR analysis ( $n=3$ for each). Data are expressed as means \pm SEM. * $P<0.05,{ }^{* *} P<0.01$ versus Ctr group. 
results suggest that the NLRP3 inflammasome, and not the NLRC4 and AIM2 inflammasomes, is involved in the pathophysiological characteristics of UUO.

\section{Effects of ASC Deficiency on Tubulointerstitial Injury and Fibrosis after UUO}

Because ASC is a central component of the NLRP3 inflammasome assembly, ${ }^{2,4}$ we investigated the role of the inflammasome in the pathophysiological features of UUO using ASC-deficient $\left(A S C^{-\prime-}\right)$ mice. At baseline, $A S C^{-1-}$ mice showed no dysfunction and pathological changes in the kidney (data not shown). To examine the effect of ASC deficiency on renal injury and fibrosis after UUO, PAS and picrosirius red stainings were performed. Substantial tubulointerstitial injury and fibrosis were detected in the kidneys of WT mice 5 and 14 days after UUO (Figure 2, A-C). ASC ${ }^{-/-}$mice showed significantly less tubulointerstitial injury and kidney fibrosis than the WT mice after UUO. In addition, both WT and $A S C^{-/-}$mice showed few sclerotic kidney glomeruli (data not shown).

\section{Inflammatory Cell Infiltration and Cytokine Expression}

Because macrophages play an important role in tissue injury and fibrosis after UUO, we performed IHC analysis. The infiltration of macrophages was increased 5 days after UUO induction. However, the increase was inhibited in the kidney of $A S C^{-1-}$ mice (Figure 3A). We then assessed the infiltration of leukocytes $\left(\mathrm{CD} 45^{+}\right)$, macrophages $\left(\mathrm{CD} 45^{+} \mathrm{CD} 11 \mathrm{~b}^{+} \mathrm{F} 4 / 80^{+}\right)$, $\mathrm{T}$ cells $\left(\mathrm{CD} 45^{+} \mathrm{CD} 3^{+} \mathrm{CD} 19^{-}\right)$, B cells $\left(\mathrm{CD} 45^{+} \mathrm{CD} 3^{-} \mathrm{CD} 19^{+}\right)$, and neutrophils $\left(\mathrm{CD} 45^{+} \mathrm{Gr}^{+} \mathrm{CD} 45 \mathrm{R}^{-}\right)$in the kidney using flow cytometric analysis and found that all of these inflammatory cells were significantly increased after UUO induction, which was significantly inhibited in the $A S C^{-/}$mice (Figure 3, $\mathrm{B}-\mathrm{D})$.

Because the inflammasome regulates production of the pivotal inflammatory cytokine, IL- $1 \beta$, we determined the expression of inflammatory cytokines after UUO induction. Real-time RT-PCR analysis showed that the mRNA expression of Illb, Ccl2, Il6, and Tnfa was significantly increased in the UUO kidneys of WT mice (Figure 4A). The expression of these inflammatory cytokines was found to be reduced in the UUO kidneys of $A S C^{-1-}$ mice. These findings indicate that $A S C^{-/-}$mice exhibit decreased inflammatory responses, such
A

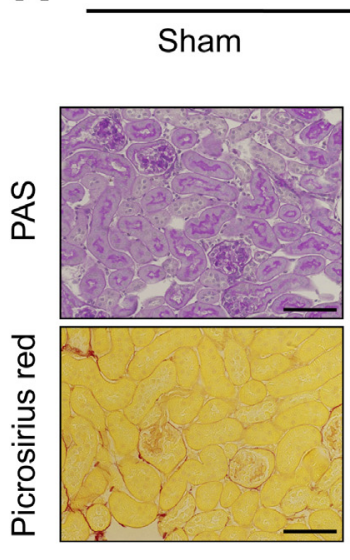

B

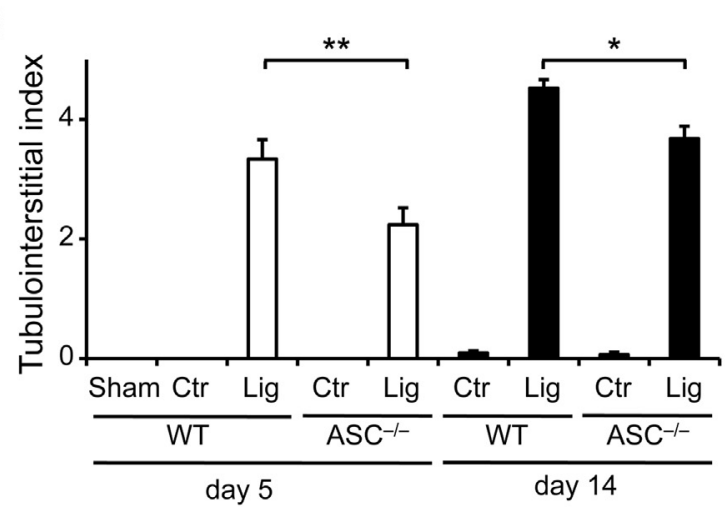

day 5

Lig

(WT)
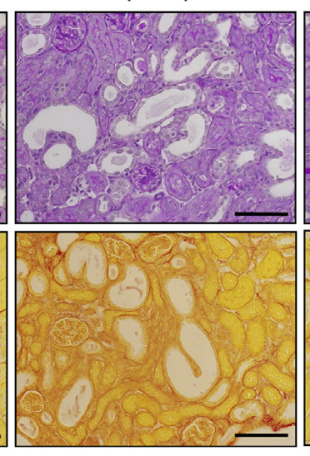

day 14

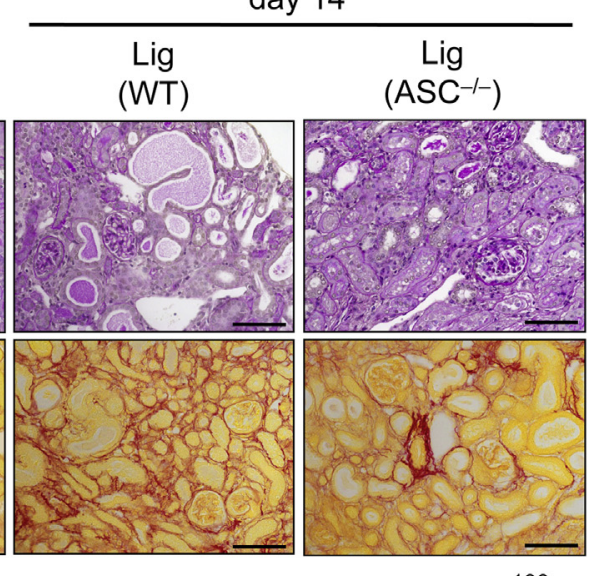

C

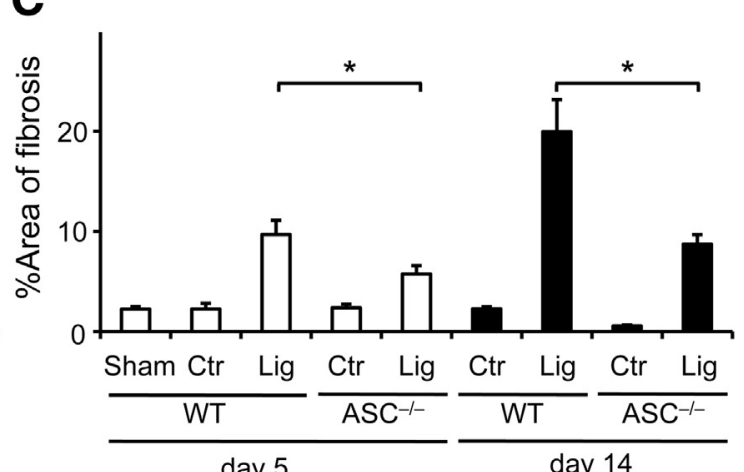

Figure 2 Tubulointerstitial injury and fibrosis. Mice were sacrificed 5 and 14 days after sham operation and UUO induction. The sham-operated on, contralateral (Ctr), and ligated (Lig) kidneys of WT and $\mathrm{ASC}^{-1-}$ mice were obtained. A: Representative PAS and picrosirius red staining of the sham-operated on, Ctr, and Lig kidneys 5 days after UU0. Quantitative analyses of tubulointerstitial index (B) and fibrotic areas (C) ( $n=5$ to 10 for each). Data are expressed as means \pm SEM. ${ }^{*} P<0.05,{ }^{*} P<0.01$. 
A
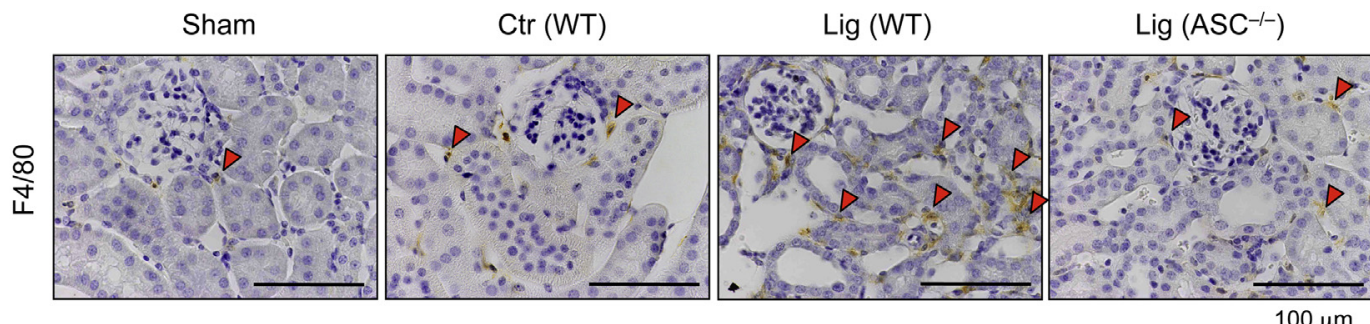

B
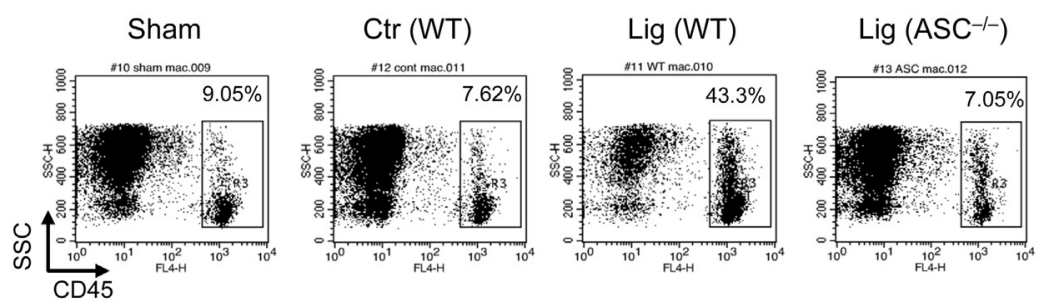

C
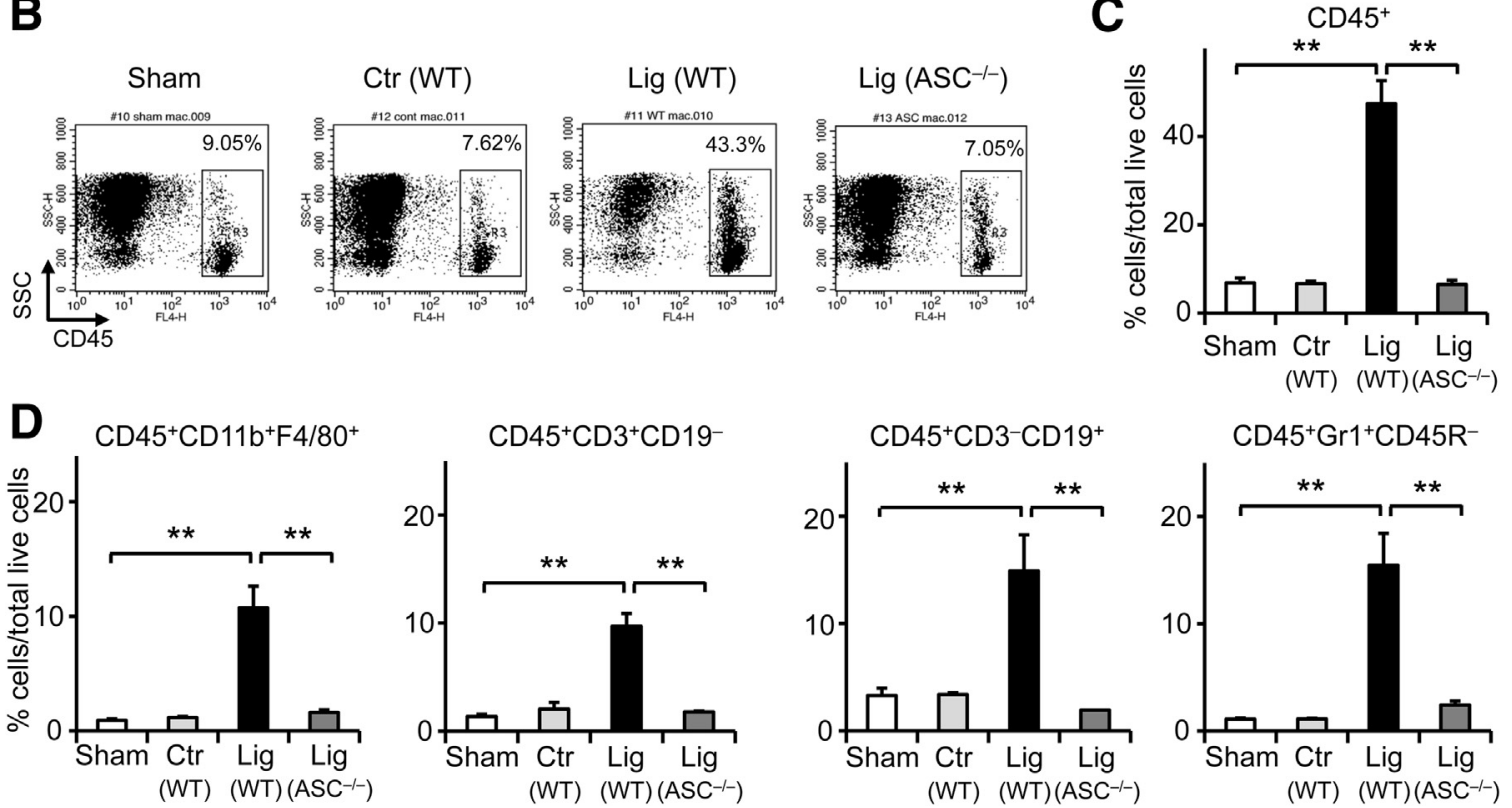

Figure 3 Inflammatory cell infiltration. Mice were sacrificed 5 days after sham operation and UUO induction. The contralateral (Ctr) and ligated (Lig) kidneys of WT and $\mathrm{ASC}^{-1-}$ mice were obtained. Inflammatory cell infiltration was analyzed by IHC and flow cytometric analyses. A: Immunostaining of the kidney sections with an antibody against the macrophage marker F4/80. Representative images of macrophage staining are shown. Arrowheads indicate F4/80-positive cells. B: Representative flow cytometry plots of infiltrated leukocytes (CD45 $\left.{ }^{+}\right)$. C: Corresponding quantitative analysis $(n=3$ for each). D: Quantitative analysis of macrophages $\left(\mathrm{CD} 11 \mathrm{~b}^{+} / \mathrm{F} 4 / 80^{+}\right)$, T cells $\left(\mathrm{CD}^{+} / \mathrm{CD}^{-} 9^{-}\right)$, B cells $\left.\left(\mathrm{CD} 3^{-} / \mathrm{CD}\right)^{+}\right)$, and neutrophils $\left(\mathrm{Gr} 1^{+} / \mathrm{CD} 45 \mathrm{R}^{-}\right)(n=3$ for each). Data are expressed as means \pm SEM. ${ }^{*} P<0.05,{ }^{* *} P<0.01$.

as inflammatory cell infiltration and cytokine expression, in the kidney after UUO.

\section{Expression of Fibrosis-Related Factors and Apoptosis}

Because myofibroblasts are characterized by the presence of $\alpha$-SMA, we performed IHC staining and found that the area of $\alpha$-SMA-positive myofibroblasts was notably increased at 5 days after UUO in WT mice, and this increase was reduced in $A S C^{-/-}$mice (Figure 4B). We also determined the expression of other factors associated with fibrotic responses after UUO induction. As expected from increased renal fibrosis, mRNA expression levels of Col1a1 and Col3a1, encoding collagen types I and III, respectively, and Tgfb1, Mmp2, Mmp9, and Timp1 were all increased markedly at 5 days after UUO in WT mice, and the increased expression of Col1a1, Col3a1, Tgfb1, Mmp2, Mmp9, and Timp1 was decreased in $A S C^{-/-}$mice (Figure 4C).

To assess the role of apoptosis after UUO, we performed TUNEL staining. Consistent with a previous report, ${ }^{16}$ few apoptotic cells were detected in the ligated kidneys of WT and $A S C^{-1-}$ mice (Supplemental Figure S1). Quantitative analysis showed no significant difference in apoptotic cells in the UUO kidneys between these mice.

\section{ASC Expression in CD Epithelial Cells}

To investigate which cell types are responsible for ASC upregulation after UUO, we performed IHC staining to detect ASC expression. In the sham-operated on kidney, few ASC-positive cells were detected (Figure 5, A and B). However, ASC was clearly up-regulated in the renal cortex and medulla 5 days after UUO. Serial sections that were stained with AQP2 (a marker for CD), AQP1 (a marker for proximal tubule), and calbindin-D28 (CaBP-D ${ }_{28 \mathrm{k}}$; a marker for distal convoluted tubule and connecting tubule) suggested ASC colocalized with AQP2, but not with AQP1 (Figure $5 \mathrm{C}$ ). CaBP-D $28 \mathrm{k}$ was partially positive in ASCpositive tubules; however, it distributed mostly in the cortex. Colocalization of ASC and APQ2 was visualized by double immunostaining (Figure 5D). Furthermore, 

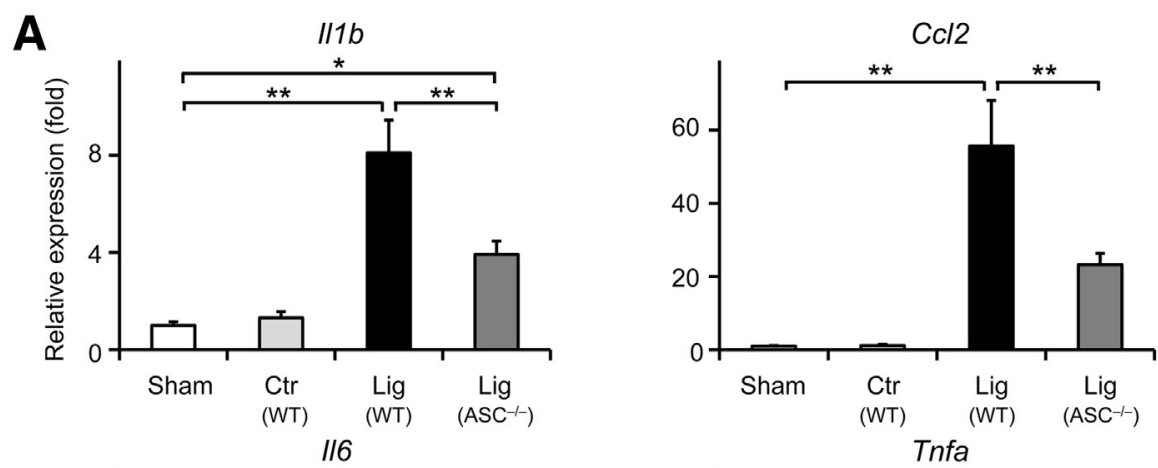

Figure 4 Expression of inflammatory cytokines and fibrosis-related factors. Mice were sacrificed 5 days after sham operation and UUO induction. The contralateral (Ctr) and ligated (Lig) kidneys of WT and $\mathrm{ASC}^{-1}$ mice were obtained. A: After total RNA was extracted, mRNA levels of Il1b, Ccl2, Il6, and Tnfa were assessed by real-time RT-PCR analysis $(n=5,8,8$, and 10 for each, respectively). Data are expressed as means \pm SEM. B: Representative images of $\alpha$-SMA immunostaining. C: mRNA levels of Col1a1, Col3a1, Tgfb1, Mmp2, Mmp9, and Timp1 using real-time RT-PCR analysis after total RNA extraction ( $n=5,8,8$, and 10 for each). Data are expressed as means \pm SEM.

B

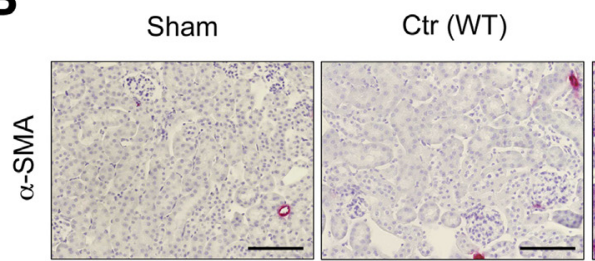
$\operatorname{Lig}(\mathrm{WT})$

$\operatorname{Lig}\left(\mathrm{ASC}^{-/-}\right)$
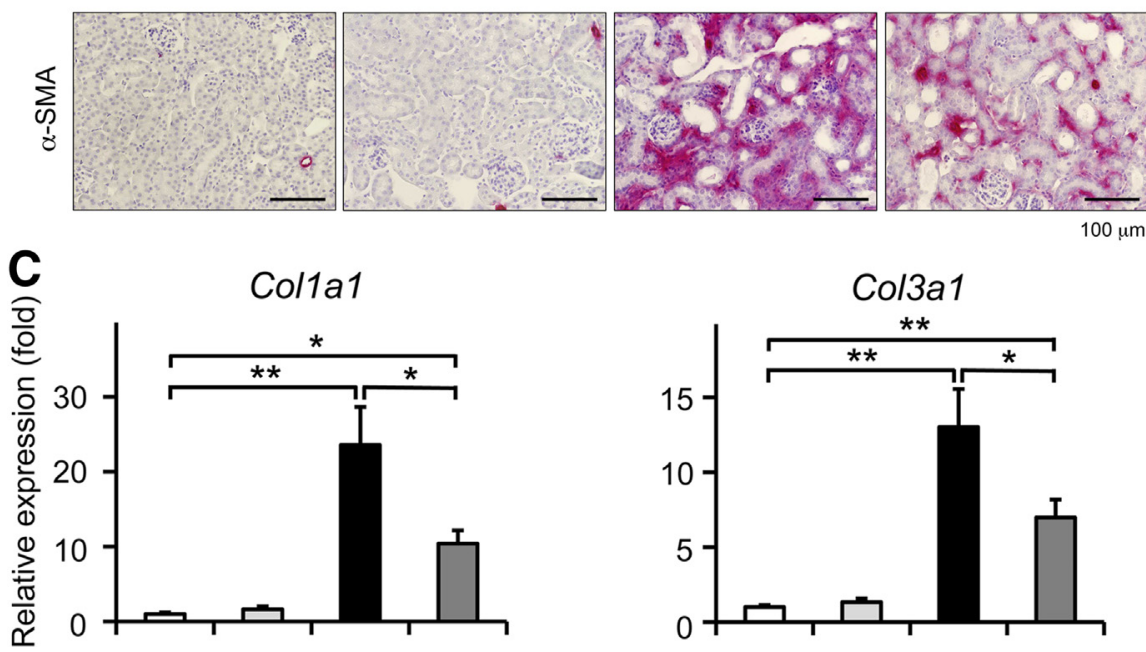

Col3a1
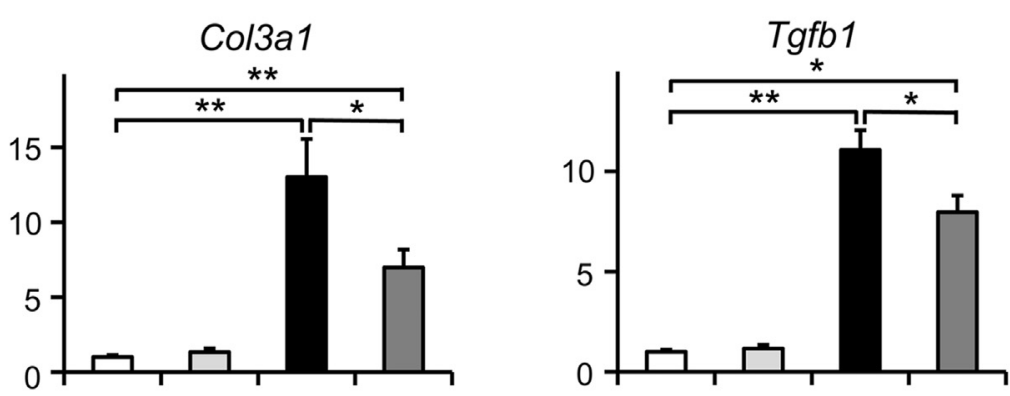

Mmp2

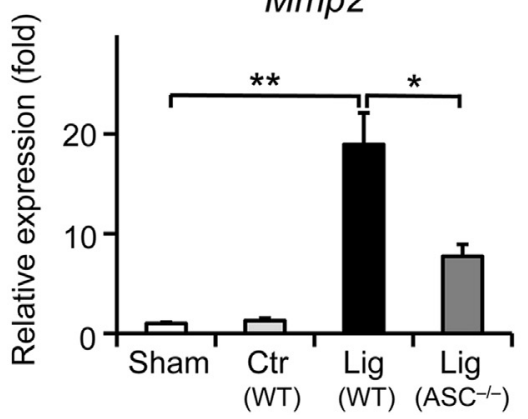

Mmp9

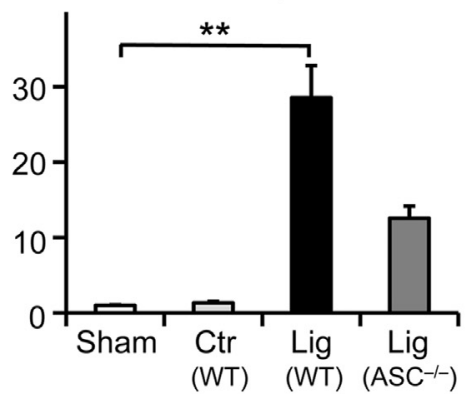

Timp1

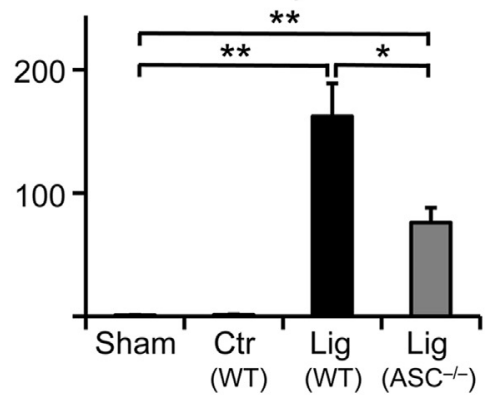

double-immunofluorescence analysis confirmed that several ASC-positive tubules in the medulla colocalized with AQP2 (Figure 5, E and F). ASC expression was also detected in the infiltrated macrophages (F4/80) of the UUO kidney (Supplemental Figure S2).
Mechanisms of Inflammasome Activation in the Kidney

To investigate the molecular mechanisms of ASC upregulation in UUO, we cultured primary CD epithelial cells in vitro. Western blot analysis showed the presence 


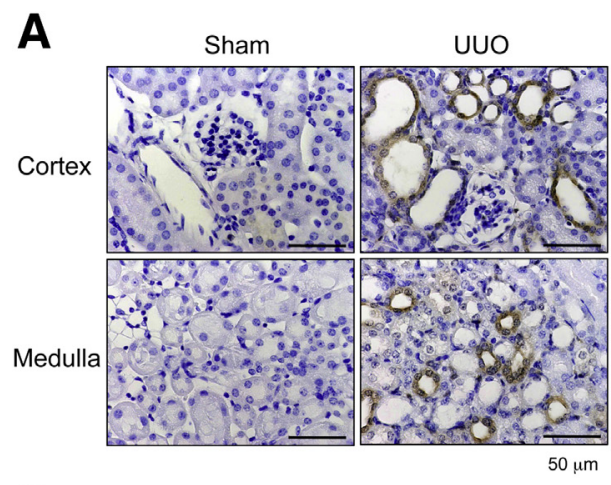

\section{B}

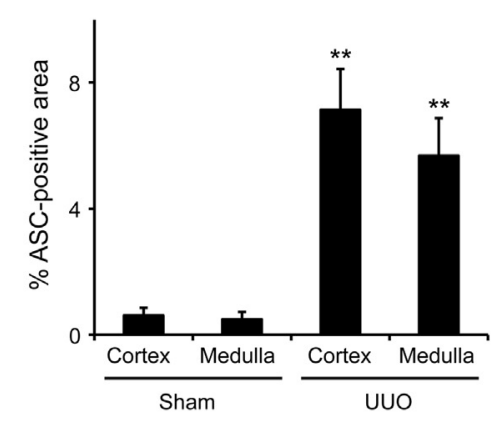

C

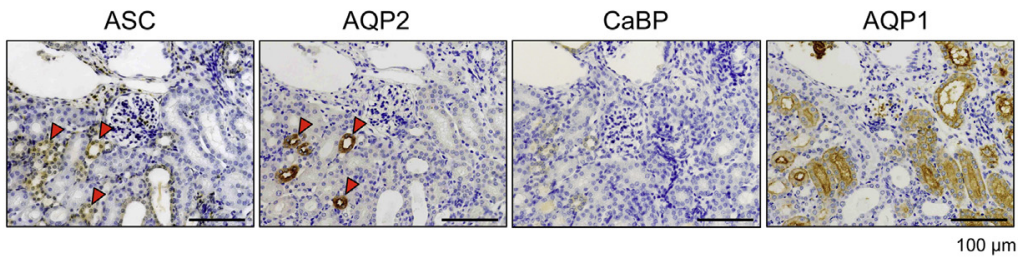

D ASC/AQP2

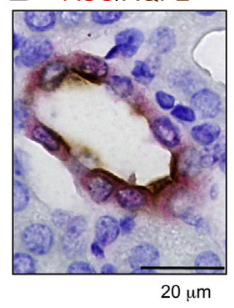

E

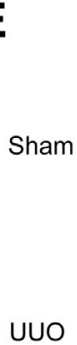

UUO

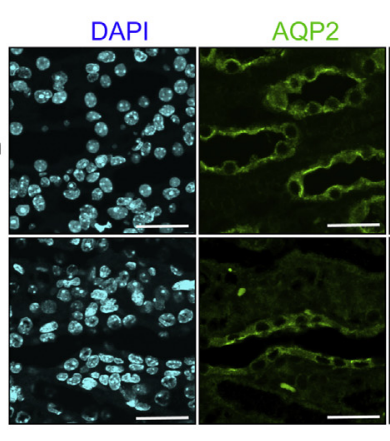

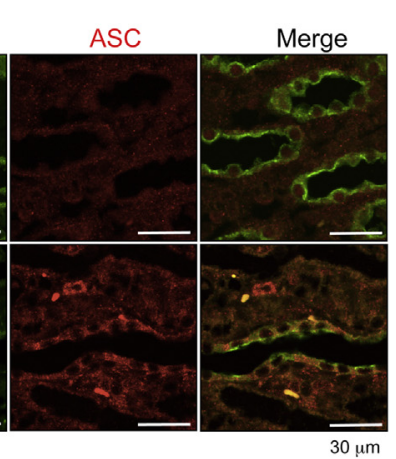

\section{$\mathbf{F}$}

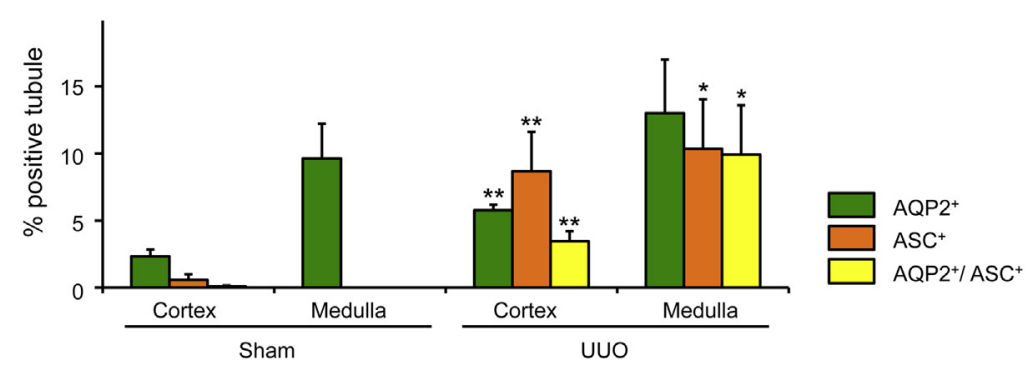

of NLRP3 and ASC in cultured CD epithelial cells (Figure 6A). Peritoneal macrophages isolated from WT, $\mathrm{NLRP}^{-/-}$, and $A S C^{-/-}$mice were used as a positive or negative control. These results indicate that $\mathrm{CD}$ epithelial cells contain the structural components of the inflammasome assembly. Because ATP was shown to be released from cells because of cell damage and/or mechanical stress, ${ }^{17}$ we examined the effect of extracellular ATP on inflammasome activation in $\mathrm{CD}$ epithelial cells. The cells were primed with low-dose LPS to ensure the induction of pro-IL-1 $\beta$, as in published studies. ${ }^{6,18,19}$ Extracellular ATP induced robust release of IL-1 $\beta$ in the primed CD epithelial cells. As expected, this IL-1 $\beta$ release was completely inhibited in the $\mathrm{CD}$ epithelial cells isolated from $A S C^{-/-}$mice (Figure $6 \mathrm{~B}$ ). Western blot analysis showed that ATP stimulated
Figure 5 ASC expression in CD epithelial cells. Mice were sacrificed 5 days after sham operation and UUO induction. Kidney sections were obtained from the cortex and medulla of WT mice. A: Representative images of ASC immunostaining of sections with an antibody against ASC. B: Quantitative analysis of ASC-positive cells ( $n=5$ to 6 for each). C: The serial sections were stained with ASC, AQP2 (CD), CaBP-D $28 \mathrm{k}$ (distal convoluted tubule and connecting tubule), and AQP1 (proximal tubule). Arrowheads indicate ASC- and AQP2-positive cells. D: Staining of the sections with ASC (red) and AQP2 (brown). E: Representative images of the doubleimmunofluorescence staining of the sections for ASC (red) and AQP2 (green). F: Quantitative analysis of ASC- and/or AQP2-positive tubules ( $n=5$ for each). Data are expressed as means \pm SEM. ${ }^{*} P<0.05,{ }^{*} * P<0.01$ processing of pro-IL-1 $\beta$ into mature IL-1 $\beta$ (Figure $6 \mathrm{C}$ ). In addition, IL-1 $\beta$ release in response to ATP was significantly prevented by treatment with a selective inhibitor for ATP purinoreceptor, $\mathrm{P}_{2} \mathrm{X}_{7}$ (A-438079) (Figure 6D). Caspase-1 activation was also confirmed by detection of the fluorescent cell-permeable probe that specifically binds to activated caspase-1 (Figure 6, E and F). To explore the possible pathways of this inflammasome activation, we performed blocking experiments with various inhibitors. ATP-induced IL-1 $\beta$ release was completely inhibited by blocking the $\mathrm{K}^{+}$ efflux from the cells by adding high-concentration extracellular $\mathrm{K}^{+}$to the culture media or by glibenclamide, an ATP-sensitive potassium channel inhibitor (Figure 6G). In addition, the role of reactive oxygen species (ROS) is implicated in ATP-induced IL-1 $\beta$ release, as demonstrated 


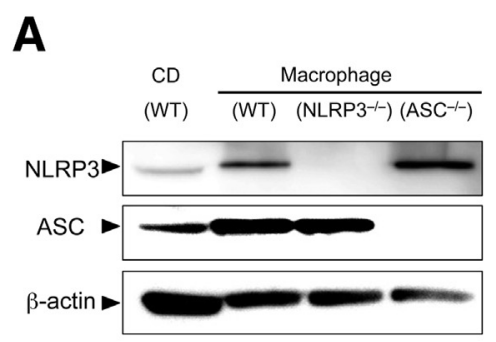

B

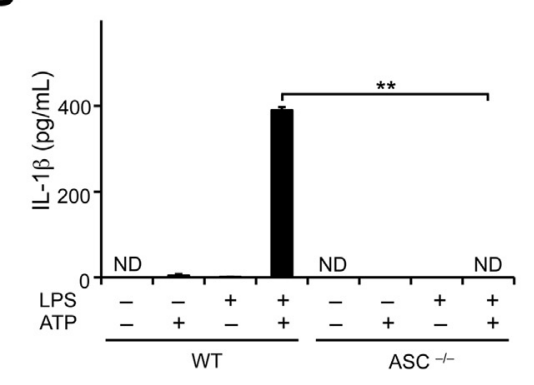

D
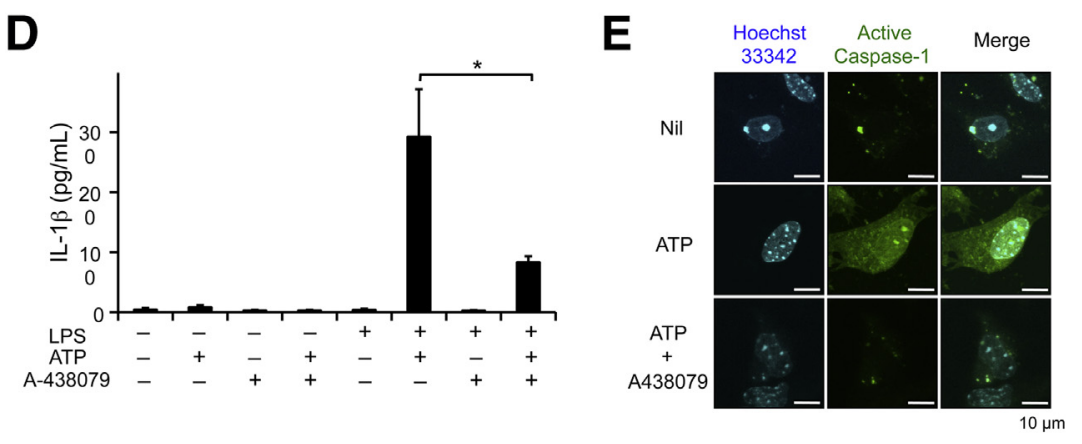

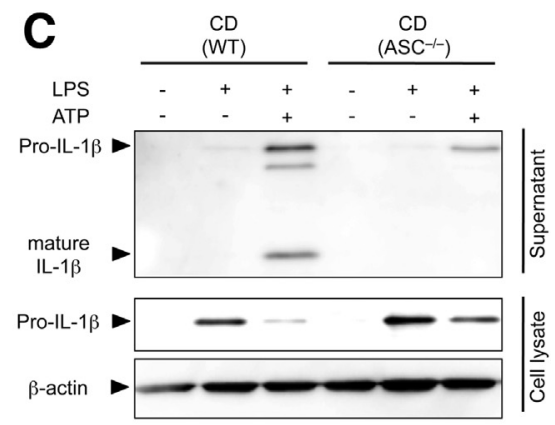

$\mathbf{F}$

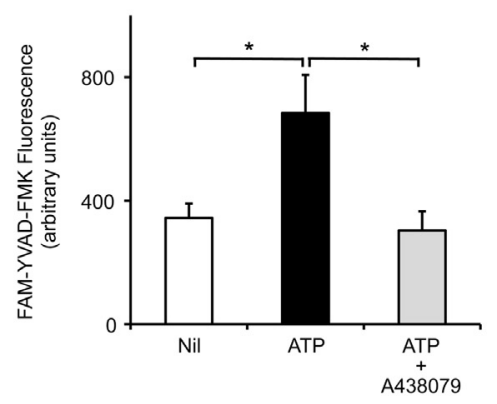

$\mathbf{G}$

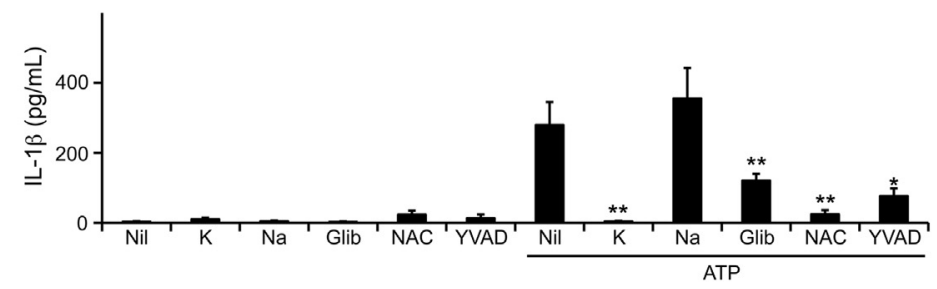

Figure 6 Mechanisms of inflammasome activation. A: Western blot analysis of primary CD cells with antibodies against NLRP3, ASC, and $\beta$-actin. Peritoneal macrophages isolated from WT and SSC $^{-1}$ - mice were used as a positive or negative control. B and C: After priming with or without $10 \mathrm{ng} / \mathrm{mL}$ LPS for 8 hours, the $\mathrm{CD}$ cells from WT and $A \mathrm{SC}^{-1-}$ mice were treated with $5 \mathrm{mmol} / \mathrm{L}$ ATP for 3 hours. The IL-1 $\beta$ levels in the supernatants $(n=3$ for each) (B) and IL-1 $\beta$ processing in the supernatants and cell lysates (C). D: LPS-primed CD cells were treated with ATP in the presence or absence of $100 \mu \mathrm{mol} / \mathrm{L}$ A-438079. The levels of IL-1 $\beta$ in the supernatants ( $n=3$ for each). E: Representative images of active caspase-1 visualized by incubation with a fluorescent cell-permeable probe that binds only to activated caspase-1. Nuclei were costained with Hoechst 33342. F: Quantitative analysis of caspase-1 activation ( $n=5$ for each). G: LPS-primed CD cells were treated with ATP in the presence or absence of a high concentration of $\mathrm{K}^{+}$or Na${ }^{+}(130 \mathrm{mmol} / \mathrm{L}), 10 \mu \mathrm{mol} / \mathrm{L} \mathrm{glibenclamide}(\mathrm{Glib}), 25$ $\mathrm{mmol} / \mathrm{L} \mathrm{NAC}$, and $20 \mu \mathrm{mol} / \mathrm{L}$ YVAD-FMK. The levels of IL-1 $\beta$ in the supernatants ( $n=4$ for each). Data are expressed as means \pm SEM. ${ }^{*} P<0.05, * * P<0.01$. ND, not detected.

by experiments using the antioxidant NAC. As expected, IL-1 $\beta$ release was blocked by the caspase-1 inhibitor, Z-Tyr-Val-Ala-Asp-fluoromethylketone (YVAD-FMK).

\section{Discussion}

The major findings of this study are as follows: i) inflammasome-related molecules were up-regulated in the kidney after UUO, ii) ASC deficiency reduced inflammatory responses, such as inflammatory cell infiltration and cytokine expression, and improved subsequent renal injury and fibrosis, iii) ASC was up-regulated in CD epithelial cells after UUO, and iv) extracellular ATP stimulated inflammasome activation in CD epithelial cells, which was mediated through $\mathrm{P} 2 \mathrm{X}_{7}$-potassium efflux and ROS-dependent pathways. The results of the present study clearly indicate that ASC upregulation in CD epithelial cells is essential for inflammation in UUO kidneys, and provide new insights into the role of the inflammasome in kidney disease.

Increasing evidence indicates that sterile inflammation contributes to renal injury and fibrosis in the progression of $\mathrm{CKD}^{20}$; however, it remains unclear how sterile inflammation is triggered in the kidney. In the present study, we demonstrated that mice deficient in ASC, a central component of the NLRP3 inflammasome assembly, exhibited significantly reduced inflammatory responses after ureteral obstruction, thereby resulting in less renal injury and fibrosis. Similar to our findings, Vilaysane et $\mathrm{al}^{9}$ recently reported that NLRP3-deficient mice had reduced inflammatory responses, tubular injury, and fibrosis after ureteral obstruction. However, the role of the 
NLRP3 inflammasome during ureteral obstruction remains controversial, because several reports described that NLRP3 or ASC shows an inflammasome-independent role in certain disease models. For instance, Shigeoka et al ${ }^{10}$ reported that reduced renal $\mathrm{I} / \mathrm{R}$ injury was observed in mice deficient for NLRP3, but not ASC or caspase-1; they concluded that an NLRP3-dependent, inflammasomeindependent pathway may contribute to the development of $\mathrm{I} / \mathrm{R}$ injury in the kidney. Because the present study suggests that the NLRP3 inflammasome can mediate renal injury and fibrosis after UUO, we speculate that the contribution of the inflammasome in the kidney depends on the disease model used.

The renal CD plays an important role in the control of fluid and electrolyte homeostasis. Recent studies also suggest the role of $\mathrm{CD}$ epithelial cells in the development of renal tubulointerstitial fibrosis in response to tubular injury via epithelial-mesenchymal transition. ${ }^{21}$ In the present study, we identified a new role for CD epithelial cells in initiating inflammatory responses in the process of CKD. We showed that the inflammasome was present in $\mathrm{CD}$ epithelial cells in vivo and that extracellular ATP activated the inflammasome in primary $\mathrm{CD}$ epithelial cells in vitro. These results indicate the $\mathrm{CD}$ epithelial cells as sentinel cells that can sense danger signals and promote inflammasome activation. Supporting our findings, Chassin et $\mathrm{al}^{22,23}$ recently reported that $\mathrm{CD}$ epithelial cells actively recognize uropathogenic bacteria, such as Escherichia coli, and initiate inflammatory responses, indicating the role of antibacterial defenses of kidney CD epithelial cells. Similarly, Fujiu et $\mathrm{al}^{24}$ recently showed that the transcription factor, Krüppel-like factor-5, is mainly expressed in CD epithelial cells and is essential for inflammatory responses to ureteral obstruction. On the other hand, it is known that ASC is highly expressed in inflammatory cells and plays a key role in initiating inflammatory responses. ${ }^{2}$ Consistently, we also observed ASC expression in the infiltrated macrophages of UUO kidney. Taken together, inflammatory cells and CD epithelial cells play a role in renal inflammation triggered by infectious and sterile danger signals.

Numerous danger signals released during renal stress and injury can activate the NLRP3 inflammasome, including ROS, extracellular ATP, uric acid, nucleic acid, and extracellular matrix components, such as hyaluronan and biglycan. $^{2}$ Of these, because ATP has been shown to be released from cells because of cell damage and/or mechanical stress, including shear stress, stretch, and osmotic swelling, ${ }^{17}$ which are related to ureteral obstruction, we examined whether extracellular ATP activates the inflammasome in CD epithelial cells. We confirmed that $\mathrm{CD}$ epithelial cells contain NLRP3 inflammasome components and found that extracellular ATP clearly stimulated caspase- 1 activation and subsequent IL-1 $\beta$ processing and release in CD epithelial cells. Interestingly, $\mathrm{CD}$ epithelial cells showed different responses from macrophages to some inflammasome-activating ligands. Monosodium urate and tricalcium phosphate crystals, which had been shown to activate inflammasome in macrophages, failed to stimulate IL-1 $\beta$ release in CD epithelial cells (data not shown).

The ATP-induced inflammasome activation in CD epithelial cells was prevented by inhibition of $\mathrm{P} 2 \mathrm{X}_{7}$, which is the purinoreceptor for extracellular ATP. Consistently, $\mathrm{P} 2 \mathrm{X}_{7}$-deficient mice exhibited not only less tubular injury and reduced inflammation and fibrosis after UUO, but also reduced inflammasome activation and renal injury in a murine model of metabolic syndrome. ${ }^{25,26}$ These findings indicate that extracellular ATP could trigger inflammasome activation in the kidney, although it is difficult to assess extracellular ATP in the renal tissue because most of the extracellular ATP may be rapidly hydrolyzed by ectonucleotidases under in vivo conditions. ${ }^{27}$ We further showed that ATP-induced inflammasome activation is mediated through potassium efflux and ROS. Thus, we propose the following mechanism: extracellular ATP, released from renal tissue after ureteral obstruction, activates the NLRP3 inflammasome by binding to the $\mathrm{P} 2 \mathrm{X}_{7}$ receptor, followed by potassium efflux and ROS production in CD epithelial cells. The subsequent IL-1 $\beta$ release results in the initial inflammatory responses, which stimulate release of chemokines and recruitment of inflammatory cells to the injured renal tissues. Furthermore, inflammasome activation in the infiltrated inflammatory cells enhances renal injury and tubulointerstitial fibrosis. During the preparation of this article, Wang et $\mathrm{al}^{28}$ reported that NLRP3 promoted renal tubular epithelialmesenchymal transition by enhancing transforming growth factor- $\beta 1$ signaling and receptor-regulated Smad activation in cultured tubular epithelial cells. Therefore, further studies are needed to elucidate the molecular link between the inflammasome and the development of CKD.

Several limitations of this study should be noted. First, although we detected up-regulation of Nlrc4 and Aim 2 mRNA in the UUO kidney, their roles in the ureteral obstruction are unclear. Second, although infiltration of inflammatory cells was markedly inhibited in ASC mice, there was no difference of tumor necrosis factor (TNF)- $\alpha$ expression between WT and $A S C^{-/-}$mice. In this regard, TNF- $\alpha$ has shown to be produced primarily by the tubular cells, and this TNF- $\alpha$ production is independent of infiltrating inflammatory cells. ${ }^{29}$ Third, although IL-1 $\beta$ production requires two distinct signals, such as the first priming signal to induce pro-IL- $1 \beta$ and the second signal to activate the inflammasome, we have not identified the first signal in ureteral obstruction. Because ureteral obstruction induces NF- $\kappa \mathrm{B}$ activation, we speculate that the first signal can be provided by the NF- $\kappa \mathrm{B}$ pathway. ${ }^{30}$ Thus, further investigations are necessary to understand the precise role of ASC in renal injury after ureteral obstruction.

\section{Conclusions}

We demonstrated that NLRP3 inflammasome was upregulated in the kidney after UUO and ASC deficiency reduced inflammatory cell infiltration and cytokine 
expression and improved subsequent renal injury and fibrosis. Although it was documented that NLRP3 deficiency improved renal injury and fibrosis after ureteral obstruction, ${ }^{9}$ contribution of other inflammasome components remains to be investigated, because NLRP3 has been shown to play an inflammasome-independent role in renal I/ $\mathrm{R}$ injury. ${ }^{10}$ Our results indicate a crucial role of the inflammasome in renal injury after ureteral obstruction and clarify the molecular inflammatory events during ureteral obstruction. Furthermore, these findings suggest the importance of the inflammasome in the pathogenesis of CKD, and that modulation of the inflammasome might be a potential target for the prevention and treatment of CKD.

\section{Acknowledgments}

We thank Sumiyo Watanabe, Masako Sakurai, Yumi Ohde, and Yuko Watanabe for their technical assistance and Drs. Takashi Satoh, Neotomo Kambe (Chiba University Graduate School of Medicine), and Toshihiko Suzuki (University of the Ryukyus) for invaluable suggestions.

\section{Supplemental Data}

Supplemental material for this article can be found at http://dx.doi.org/10.1016/j.ajpath.2014.01.014.

\section{References}

1. US Renal Data System: USRDS 2012 Annual Data Report: Atlas of Chronic Kidney Disease \& End-Stage Renal Disease in the United States. NIH, National Institute of Diabetes and Digestive and Kidney Diseases, Bethesda, MD, 2012

2. Davis BK, Wen H, Ting JP: The inflammasome NLRs in immunity, inflammation, and associated diseases. Annu Rev Immunol 2011, 29: 707-735

3. Chen GY, Nunez G: Sterile inflammation: sensing and reacting to damage. Nat Rev Immunol 2010, 10:826-837

4. Takahashi M: Role of the inflammasome in myocardial infarction. Trends Cardiovasc Med 2011, 21:37-41

5. Yajima N, Takahashi M, Morimoto H, Shiba Y, Takahashi Y, Masumoto J, Ise H, Sagara J, Nakayama J, Taniguchi S, Ikeda U: Critical role of bone marrow apoptosis-associated speck-like protein, an inflammasome adaptor molecule, in neointimal formation after vascular injury in mice. Circulation 2008, 117:3079-3087

6. Kawaguchi M, Takahashi M, Hata T, Kashima Y, Usui F, Morimoto H, Izawa A, Takahashi Y, Masumoto J, Koyama J, Hongo M, Noda T, Nakayama J, Sagara J, Taniguchi S, Ikeda U: Inflammasome activation of cardiac fibroblasts is essential for myocardial ischemia/reperfusion injury. Circulation 2011, 123:594-604

7. Usui F, Shirasuna K, Kimura H, Tatsumi K, Kawashima A, Karasawa T, Hida S, Sagara J, Taniguchi S, Takahashi M: Critical role of caspase-1 in vascular inflammation and development of atherosclerosis in Western diet-fed apolipoprotein E-deficient mice. Biochem Biophys Res Commun 2012, 425:162-168

8. Duewell P, Kono H, Rayner KJ, Sirois CM, Vladimer G, Bauernfeind FG, Abela GS, Franchi L, Nunez G, Schnurr M, Espevik T, Lien E, Fitzgerald KA, Rock KL, Moore KJ, Wright SD, Hornung V, Latz E: NLRP3 inflammasomes are required for atherogenesis and activated by cholesterol crystals. Nature 2010, 464: $1357-1361$

9. Vilaysane A, Chun J, Seamone ME, Wang W, Chin R, Hirota S, Li Y, Clark SA, Tschopp J, Trpkov K, Hemmelgarn BR, Beck PL, Muruve DA: The NLRP3 inflammasome promotes renal inflammation and contributes to CKD. J Am Soc Nephrol 2010, 21:1732-1744

10. Shigeoka AA, Mueller JL, Kambo A, Mathison JC, King AJ, Hall WF, Correia Jda S, Ulevitch RJ, Hoffman HM, McKay DB: An inflammasome-independent role for epithelial-expressed Nlrp3 in renal ischemia-reperfusion injury. J Immunol 2010, 185: $6277-6285$

11. Yamamoto M, Yaginuma K, Tsutsui H, Sagara J, Guan X, Seki E, Yasuda K, Yamamoto M, Akira S, Nakanishi K, Noda T, Taniguchi S: ASC is essential for LPS-induced activation of procaspase-1 independently of TLR-associated signal adaptor molecules. Genes Cells 2004, 9:1055-1067

12. Chevalier RL, Forbes MS, Thornhill BA: Ureteral obstruction as a model of renal interstitial fibrosis and obstructive nephropathy. Kidney Int 2009, 75:1145-1152

13. Vielhauer V, Anders HJ, Perez de Lema G, Luckow B, Schlondorff D, Mack M: Phenotyping renal leukocyte subsets by four-color flow cytometry: characterization of chemokine receptor expression. Nephron Exp Nephrol 2003, 93:e63

14. Ohtaka A, Muto S, Nemoto J, Kawakami K, Nagano K, Asano Y: Hyperosmolality stimulates Na-K-ATPase gene expression in inner medullary collecting duct cells. Am J Physiol 1996, 270: F728-F738

15. Burger-Kentischer A, Muller E, Marz J, Fraek ML, Thurau K, Beck FX: Hypertonicity-induced accumulation of organic osmolytes in papillary interstitial cells. Kidney Int 1999, 55:1417-1425

16. Matsuo S, Lopez-Guisa JM, Cai X, Okamura DM, Alpers CE, Bumgarner RE, Peters MA, Zhang G, Eddy AA: Multifunctionality of PAI-1 in fibrogenesis: evidence from obstructive nephropathy in PAI1-overexpressing mice. Kidney Int 2005, 67:2221-2238

17. Communi D, Janssens R, Suarez-Huerta N, Robaye B, Boeynaems JM: Advances in signalling by extracellular nucleotides: the role and transduction mechanisms of P2Y receptors. Cell Signal 2000, 12: $351-360$

18. Mariathasan S, Weiss DS, Newton K, McBride J, O'Rourke K, RooseGirma M, Lee WP, Weinrauch Y, Monack DM, Dixit VM: Cryopyrin activates the inflammasome in response to toxins and ATP. Nature 2006, 440:228-232

19. Dostert C, Petrilli V, Van Bruggen R, Steele C, Mossman BT, Tschopp J: Innate immune activation through Nalp3 inflammasome sensing of asbestos and silica. Science 2008, 320:674-677

20. Anders HJ, Muruve DA: The inflammasomes in kidney disease. J Am Soc Nephrol 2011, 22:1007-1018

21. Butt MJ, Tarantal AF, Jimenez DF, Matsell DG: Collecting duct epithelial-mesenchymal transition in fetal urinary tract obstruction. Kidney Int 2007, 72:936-944

22. Chassin C, Goujon JM, Darche S, du Merle L, Bens M, Cluzeaud F, Werts C, Ogier-Denis E, Le Bouguenec C, Buzoni-Gatel D, Vandewalle A: Renal collecting duct epithelial cells react to pyelonephritis-associated Escherichia coli by activating distinct TLR4dependent and -independent inflammatory pathways. J Immunol 2006, $177: 4773-4784$

23. Chassin C, Vimont S, Cluzeaud F, Bens M, Goujon JM, Fernandez B, Hertig A, Rondeau E, Arlet G, Hornef MW, Vandewalle A: TLR4 facilitates translocation of bacteria across renal collecting duct cells. J Am Soc Nephrol 2008, 19:2364-2374

24. Fujiu K, Manabe I, Nagai R: Renal collecting duct epithelial cells regulate inflammation in tubulointerstitial damage in mice. J Clin Invest 2011, 121:3425-3441

25. Goncalves RG, Gabrich L, Rosario A Jr, Takiya CM, Ferreira ML, Chiarini LB, Persechini PM, Coutinho-Silva R, Leite M Jr: The role of purinergic $\mathrm{P} 2 \mathrm{X} 7$ receptors in the inflammation and fibrosis of unilateral ureteral obstruction in mice. Kidney Int 2006, 70:1599-1606 
26. Solini A, Menini S, Rossi C, Ricci C, Santini E, Blasetti Fantauzzi C, Iacobini C, Pugliese G: The purinergic 2X7 receptor participates in renal inflammation and injury induced by high-fat diet: possible role of NLRP3 inflammasome activation. J Pathol 2013, 231:342-353

27. Eckle T, Fullbier L, Wehrmann M, Khoury J, Mittelbronn M, Ibla J, Rosenberger P, Eltzschig HK: Identification of ectonucleotidases CD39 and CD73 in innate protection during acute lung injury. J Immunol 2007, 178:8127-8137

28. Wang W, Wang X, Chun J, Vilaysane A, Clark S, French G, Bracey NA, Trpkov K, Bonni S, Duff HJ, Beck PL, Muruve DA:
Inflammasome-independent NLRP3 augments TGF-beta signaling in kidney epithelium. J Immunol 2013, 190:1239-1249

29. Misseri R, Meldrum DR, Dagher P, Hile K, Rink RC, Meldrum KK: Unilateral ureteral obstruction induces renal tubular cell production of tumor necrosis factor-alpha independent of inflammatory cell infiltration. J Urol 2004, 172:1595-1599; discussion 9

30. Esteban V, Lorenzo O, Ruperez M, Suzuki Y, Mezzano S, Blanco J, Kretzler M, Sugaya T, Egido J, Ruiz-Ortega M: Angiotensin II, via AT1 and AT2 receptors and NF-kappaB pathway, regulates the inflammatory response in unilateral ureteral obstruction. J Am Soc Nephrol 2004, 15:1514-1529 